\title{
ESTIMATION AND ITS IMPORTANCE IN EGINEERING EDUCATION
}

\author{
Said Shakerin, Ph.D., P.E. (sshakerin@pacific.edu) \\ Department of Mechanical Engineering \\ University of the Pacific \\ Stockton, CA 95211
}

\begin{abstract}
Ability to perform estimation is an asset, for example, when dealing with problems with limited or unavailable data. Engineering students, in general, are inadequately prepared to perform rough estimation. A possible reason for this short coming is that engineering curricula place too much emphasis on detailed analysis and not enough attention is given to developing estimation skill. This paper provides a list of activities, appropriate at lower division courses, to engage students in estimation exercises and to lunch them on a path to develop this skill.
\end{abstract}

\section{Introduction}

Estimation is an integral activity of our daily lives - from determining how much cash to take along during our upcoming vacation to purchasing enough paint to add some color to our home. Considering the latter, if our estimate is way off, we either end up with a lot of extra paint or need to make another trip to the paint shop to purchase more. Being able to properly estimate various quantities that one encounters is a useful skill. People use experience and common sense and read labels and instructions to perform these estimations, which usually require simple arithmetic.

Engineers also make use of estimation in their practice to determine answers to ill-defined problems or when a detailed solution is not called for. Estimation particularly plays an important role in preliminary stages of design process when decisions have to be made based on incomplete or unavailable details/data, and selections must be made from a multitude of options. Engineering estimation $\left(\mathrm{E}^{2}\right)$ covers a large domain between detailed analysis (time consuming and expensive) and guessing (instantly done and free). Successful $\mathrm{E}^{2}$ is performed based on knowledge of dimensions and units, the laws of physics and modeling, ability to relate and compare, and common sense. Like many other attributes, an engineer's ability to estimate is enhanced and strengthened by experience.

In the late 1990s a comprehensive study was undertaken at MIT to find out mechanical engineering students' ability to perform simple engineering estimations. The estimation questions posed to students in their survey related to energy in a small battery, drag on a bicyclist, and power output of a small motor. (The study also included students from five other top-ranked mechanical engineering programs, as well as practicing mechanical engineers for comparison purposes.) The study culminated in a Ph.D. dissertation by Linder [1] and resulted in a number of publications [e.g., 2 and 3]. The reader is encouraged to consult with these 
references as they document details of the survey and findings with profound implications in engineering education. Two important conclusions of the study are quoted below.

(1) "Students were found to have considerable difficulty making estimates for common engineering quantities, such as force and energy."

(2) "Students were also found to have difficulty applying basic engineering concepts in rough estimation situations even at the senior level."

After reading the MIT study, the author became curious about how well University of the Pacific (UOP) engineering students would perform $\mathrm{E}^{2}$. He conducted a survey, borrowed from the MIT study, in engineering Mentor III course in spring 2003. Students in the two sections of this course were graduating seniors ${ }^{1}$ from all engineering majors. Each question used in the estimation survey was given as an impromptu, five-minute in-class activity. There were two questions in the survey but only one is reported here as the other one resulted in the same findings. Students were told not to write their names on their responses and that the activity had no effect on their grades in the course. The question was to estimate the energy content of a fresh 9-volt battery. Fifty-eight students participated and their numerical answers, which cover many orders of magnitude, are plotted in Figure 1. This as well as other results, as organized and tabulated in the appendix, corroborated the MIT findings that engineering students in general are not adequately prepared for even simple estimation problems and that they have problems with dimensions and units.

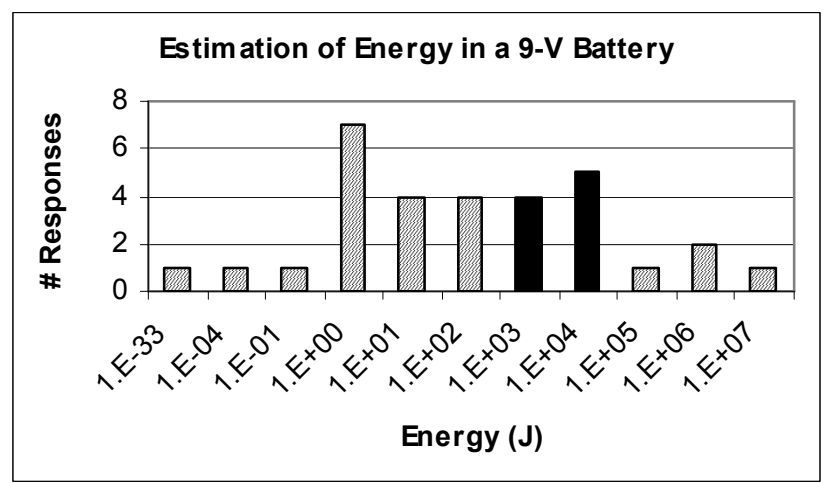

Figure 1 - Answers to estimation problem. Only those answers given in joules or equivalent are shown (31 out of 58 students).

To help alleviate the present situation, the author advocates systematical approach to expose students to estimation scenarios. Students should be encouraged to practice estimation and be made aware of its importance through short exercises with everyday objects and experiences. The more we ask students to estimate, the better they are prepared to use this skill in follow-up courses and eventually in their careers. Estimation exercises should be included in all and especially the lower division courses, where the engineering foundations are established. Examples of such courses are Introduction to Engineering and Statics where dimensions, units, and basic engineering concepts are discussed and learned. Several estimation activities

\footnotetext{
${ }^{1}$ At UOP, the engineering degree is a five-year program including one year of co-op. Thus, there are two years at the senior level.
} 
appropriate at the freshman level are presented below to illustrate examples of what can be done. These activities could be done in class or assigned as homework.

Activity \# 1 - Ask students to make a list of familiar objects to serve as easy-to-remember estimation standards for various quantities. For example, a credit card is approximately 3.5 inches long; a burning match converts chemical energy to about 3 Btus of thermal energy; a hair dryer requires about $1 \mathrm{~kW}$ of electrical power and so on. Of course, body parts such as feet and cubit (distance from elbow to fingertips) can be used for length standards. This activity can be performed by groups and then tallied on the board for the entire class to benefit. With such a list of objects in their memory, students will have a better grasp of units and how big, or small, they are. As students advance through their engineering programs they can refine and add to their list of estimation standards. A fascinating source for visual comparisons among various quantities of distance, area, weight, density, energy, temperature, etc. is a book titled Comparisons [4] published in 1980.

Activity \# 2 - Take a piece of 2 by 4 to the class and ask students to estimate its length, width, and height. Point out the difference between the nominal and exact size in the lumber industry. Considering the lecture room, ask students to estimate the number of cans of paint needed to paint the walls; i.e., estimate the surface area. Point out the standard ceiling height in a typical older residential building (room's ceiling height $\approx 8 \mathrm{ft}$ ).

Activity \# 3 - Ask students to estimate the weight of body extremities such as arms and legs. This can be done, for example, by looking at a photograph with super-imposed gridlines to estimate the percentage of body parts. With two views (front and side), fairly good estimates can be made. Simple experiments with bathroom scale can be performed to confirm. This kind of information is useful to designers of rehabilitative devices.

Activity \# 4 - Ask students to estimate the drag on a bicyclist travelling at $20 \mathrm{mph}$. This was also one of the estimation questions that were used in the MIT study. There are several methods by which drag can be estimated as documented in Linder's dissertation [1]. A related article about drag on cars appeared in Scientific American [5].

Activity \# 5 - Ask students to estimate their own physical power ${ }^{2}$. One simple way to do this is by climbing a flight of stairs. By estimating the person's weight $(\mathrm{W})$, stairs' height $(\mathrm{H})$, and the time it took to climb $(\mathrm{t})$, the change in potential energy $(\mathrm{PE}=\mathrm{W} . \mathrm{H})$, and then power $(\mathrm{P}=\mathrm{PE} /$ t) can be determined. This power is roughly $0.3 \mathrm{hp}$ for average adults, but note that it would be difficult to sustain it for long time. (For comparison, the pumping power of human heart is about $0.002 \mathrm{hp}$.) Of course, unit conversion plays an important role here; e.g., to convert from $\mathrm{lb}_{\mathrm{f} . \mathrm{ft} / \mathrm{s}}$ or N.m/s to hp. Bryan Allen, an avid bicyclist in top condition, sustained about 0.4 hp for near 3 hours as he pedaled and piloted the human-powered Gossamer Albatross in June 1979 to cross the English Channel. Point out the difference between burst and sustained amounts of power. Point out the different units of power used - hp for prime movers, $\mathrm{kW}$ for appliances, MW for

2 Two excellent books that present and discuss different quantities (size, energy, etc.) in biological organisms are On Size and Life and Exploring Biomechanics [6, 7]. 
power plants, etc. Also, point out the difference between $\mathrm{kW}$ and $\mathrm{kW} . \mathrm{h}$ as some, even senior students, have difficulty with this.

Activity \# 6 - Ask students to estimate home energy costs and compare with their monthly statements from the utility company. Important lessons about kW.h, Btu, Therm, cost, etc. can be shared via this exercise. Also, students will get a sense about the relative magnitudes of power requirements of various appliances. Utility companies might have useful information on this subject (e.g., see www.pge.com).

Activity \# 7 - Almost everybody has used 9V batteries in consumer products such as toys, smoke alarms, audio devices, etc. Yet, most people including some engineering students are clueless about the amount of energy stored in such a battery. The idea behind this activity is to conduct a simple experiment to allow students to measure this energy.

Experiment - Have different groups use fresh batteries with different brand names for comparison. Connect a 9-V battery to a light bulb (or other suitable loads such as a microprocessor cooling fan). Using an inexpensive multimeter, measure and record the battery voltage $(\mathrm{V})$ and the bulb's resistance $(\mathrm{R})$ every hour until the bulb is very $\operatorname{dim}^{3}$. Using the Ohm's law, students should be able to determine the power $\left(\mathrm{P}=\mathrm{V}^{2} / \mathrm{R}\right)$ at each measurement instant, and then calculate the energy during the entire period $(\mathrm{E}=\Sigma \mathrm{P} . \Delta \mathrm{t})$. After finishing the experiment, students will have been exposed to simple circuit and use of multimeter, Ohm's law, units of energy and power, and perhaps some safety lessons. Additionally, they will hopefully remember the amount of energy stored in a $9 \mathrm{~V}$ battery for future reference. It is interesting to compare the cost of this energy with the PG\&E (power company in California) residential rate, which is about 12 cents per $\mathrm{kW}$.h or 0.003 cents per kJ. A 9-V battery contains about $10 \mathrm{~kJ}$ and costs $\$ 3$, which results in 30 cents per kJ. A battery is indeed a very expensive, but convenient, source of electrical energy!

Activity \# 8 - Ask students to estimate power of a commercial jetliner. Students need some basic data to properly respond, and such data for both commercial and military aircrafts can be found at www.boeing.com. For example, specifications for Boeing 747-400ER, the largest in the 700 series jetliners in production, are: $\mathrm{W}_{\max }=910,000 \mathrm{lb}_{\mathrm{f}}, \mathrm{V}_{\text {cruise }}=567 \mathrm{mph}$ at $35,000 \mathrm{ft}$, engine thrust $=63,300 \mathrm{lb}_{\mathrm{f}}$. Therefore, for this aircraft, the power to takeoff and reach the cruising altitude in about 10 minutes is roughly $70 \mathrm{MW}$. In comparison, the power of Boeing 717, the smallest in production, turns out to be about $8 \mathrm{MW}$. It is interesting to note that 747 length is almost twice that of 717 , resulting in a volume (read weight) ratio of about 8 , which is close to the power ratio. This exercise will allow students to appreciate the enormous power exhibited in jetliners and get a sense for how big a MW is. It is also educational to estimate the energy content of a jetliner due to its fuel. At $132 \times 10^{6} \mathrm{~J} / \mathrm{gal}$, a gallon of jet fuel is roughly equivalent to 40,000 burning matches or $50 \mathrm{lb}$ of TNT. With tens of thousands of gallons of fuel onboard, a jetliner becomes a deadly weapon - the destructive force that brought down the Towers in the WTC tragedy in September 2001.

\footnotetext{
${ }^{3}$ Instrumenting the circuit with two multimeters to measure voltage across the bulb and current going through the bulb will yield more accurate results but the above procedure is quite adequate for our purpose.
} 
Activity \# 9 - As a follow-up exercise, ask students to report on output power of different kinds of motors such as humming bird, human heart, small DC hobby motor, car engine, power plant, rocket, etc. Power is an important quantity in all branches of engineering, and with this kind of exercise students will be able to better grasp the relative magnitudes of power among somewhat familiar objects. Figure 2 represents a graphical example of the outcome of this activity, which clearly depicts order of magnitudes among familiar objects and living systems.

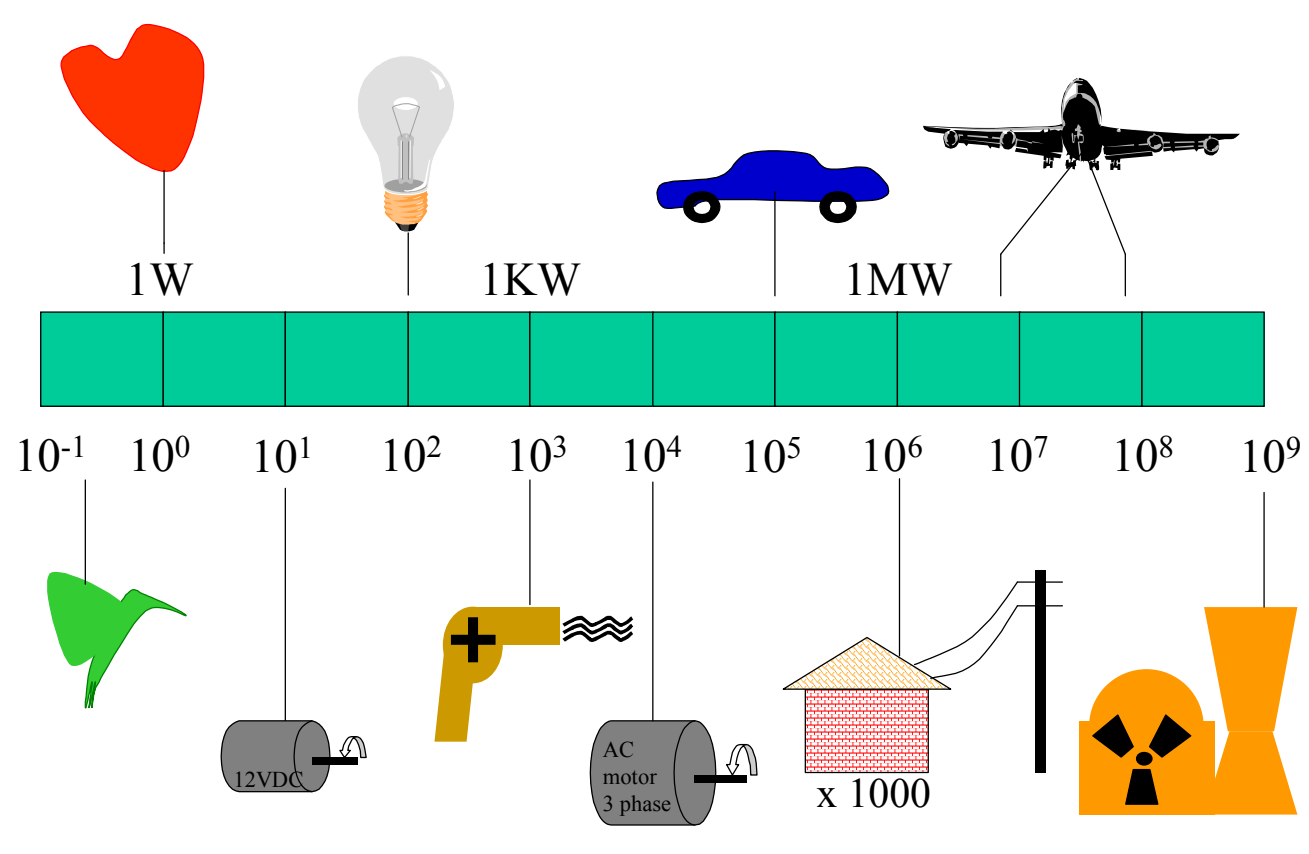

10

Figure 2 - Ten orders of magnitude among power outputs of familiar biological and engineering systems.

Overall, students should be given ample opportunities to develop $\mathrm{E}^{2}$ ability by systematically going through basic dimensions and units and working up on physical laws - applying their knowledge to common things and experiences. The above activities, as well as others available on the Internet [8], will help students in this endeavor. As implicitly mentioned earlier there is much more to $\mathrm{E}^{2}$ than units and dimensions. However, units and dimensions and simple relationships (e.g., $\mathrm{P}=\mathrm{E} / \mathrm{t}$ ) form the foundation. Once students are equipped with this, they are on the road to make estimations in more complex problems and situations.

Work done at University of the Pacific - In collaboration with colleagues, the author has integrated some of the above activities in the Introduction to Engineering course, which is a required course for all engineering students. Specifically, one formal lecture was delivered on 
estimation followed by a homework set of six problems and mini-projects, similar to the set described in this paper. One laboratory session was also dedicated to the height estimation, followed by crude measurement, of a tall building on campus. Students actively participated in these exercises. We are hoping to continue to strengthen our coverage on estimation throughout the curricula with the goal of equipping our students for this important skill.

\section{Conclusion}

Based on recent survey results, it appears engineering students are not adequately prepared to make reasonable estimation of engineering quantities. Current engineering education practice places too much emphasis on detailed analysis. For students to learn to estimate, they have to practice by doing. Nine activities were suggested to help students in developing their estimation skill. Much more needs to be done in rectifying the current deficiency in student's ability to estimate.

\section{Acknowledgements}

I am grateful for the encouragement I have received from Professors Rahim Khoie and Camilla Saviz in developing my ideas about estimation. Professor Ed Pejack suggested the experiment in activity \# 7. An earlier version of this paper was presented at the 2004 ASEEPSW Conference in Stockton, CA.

\section{References}

1. Linder, B., 1999, "Understanding Estimation and Its Relation to Engineering Education," Ph.D. Dissertaion, MIT.

2. Linder, B., and Flowers, W. C., 1996, "Students Response to Impromptu Estimation Questions," Proceedings of the 1996 ASME Design Engineering Technical Conferences and Computers in Engineering Conference, Irvine, California.

3. Linder, B., and Flowers, W. C., 2001, "Integrating Engineering Science and Design: A Definition and Discussion," International Journal of Engineering Education, Vol. 17, Nos. 4 and 5, pp. 436-439.

4. The Diagram Group, 1980, “Comparisons," St. Martin’s Press, Inc., New York, N.Y.

5. Ross, M. and DeCicco, J., 1994, "Measuring the Energy Drain on Your Car," Scientific American, December, pp. 112-115.

6. McMahon, T. A., and Bonner, J. T., 1983, "On Size and Life," Scientific American Books, Inc., New York, N.Y.

7. Alexander, R. M., 1992, "Exploring Biomechanics: Animal Locomotion," Scientific American Library, New York, N.Y.

8. Kolecki, J., "Estimation Problems," www.grc.nasa.gov. Click on Education, Learning Technologies Project, and Mathematical Thinking in Physics to reach estimation problems. 
Appendix: Estimation Survey - UOP Engineering Mentor III Classes - 17 \& 20 March 2003 Survey Question: Estimate energy stored in a new 9V battery. Write your estimation process (5 minutes).

Answer: 7,000 - 17,000 J for a small (transistor) 9V battery, depending on the brand and type.

Survey Participants:
\begin{tabular}{|l|r|r|}
\hline Majors & \# of Responses & Comments \\
\hline CpE & 16 & Students were asked to identify their majors but not \\
\hline EE & 15 & their names. \\
\hline Eph & 6 & \\
\hline CE & 10 & \\
\hline ME & 6 & \\
\hline EM & 3 \\
\hline Unknown & 2 \\
\hline Total Students & $\mathbf{5 8}$ & \\
\hline
\end{tabular}

Survey Results: organized in three sections: (1) concepts used, (2) range of answers, (3) units reported.

\begin{tabular}{|c|c|c|}
\hline 1. Concepts Used & \# of Responses & Comments \\
\hline Ohm's law \& $\mathrm{E}=\mathrm{P} \times \mathrm{t}$ & 26 & Some used these equations incorrectly. \\
\hline Wild guess & 4 & Wrote a number without any explanation. \\
\hline Others & 24 & Used various incorrect relations and explanations. \\
\hline No Idea & 2 & Actually wrote they had no idea! \\
\hline Need more information & 2 & \multirow{2}{*}{$\begin{array}{l}\text { One student correctly indicated size is important but } \\
\text { did not make any estimate. }\end{array}$} \\
\hline & & \\
\hline 2. Range of Answers, J & \# of Responses & Comments \\
\hline 1.E-33-1.E-32 & & Answers ranged from $5.9 \mathrm{E}-33$ to $3.4 \mathrm{E}+7 \mathrm{~J}$. \\
\hline 1.E-4 - 1.E-3 & 1 & \\
\hline 1.E-1 - 1.E0 & & \multirow{4}{*}{$\begin{array}{l}\text { Only answers reported in } \mathrm{J} \text { or its equivalent are } \\
\text { presented here. Several students indicated the } \\
\text { correct unit but did not provide numerical answer. }\end{array}$} \\
\hline 1.E0 - 1.E1 & & \\
\hline 1.E1-1.E2 & 4 & \\
\hline $1 . \mathrm{E} 2-1 . \mathrm{E} 3$ & 4 & \\
\hline 1.E3-1.E4 & 4 & \multirow{5}{*}{$\begin{array}{l}\text { Nine students reported their answers in the } \\
\text { acceptable range, } 1 \mathrm{E} 3-1 \mathrm{E} 5 \mathrm{~J} \text {. }\end{array}$} \\
\hline 1.E4 - 1.E5 & 5 & \\
\hline 1.E5 - 1.E6 & 1 & \\
\hline 1.E6 $6-1 . \mathrm{E} 7$ & 2 & \\
\hline 1.E7 - 1.E8 & 1 & \\
\hline 3. Units Reported & \# of Responses & Comments \\
\hline Joule & 36 & Including several that wrote W.h for the unit. \\
\hline Incorrect units & 14 & Including 7 who wrote $\mathrm{W}$ for the unit. \\
\hline None & 8 & \\
\hline
\end{tabular}

\section{Biography}

SAID SHAKERIN is professor of Mechanical Engineering at the University of the Pacific, where he has been since earning his Ph.D. from Colorado State University in 1986. He is a registered professional engineer in California, and served as department chairman from 1995 to 1998 but stepped down due to medical reason. Current scholarly activities include design of educational materials. 